\title{
Determination of Iron Ion in the Water of a Natural Hot Spring Using Microfluidic Paper-based Analytical Devices
}

\author{
Kazuma OgawA and Takashi KANETA ${ }^{\dagger}$ \\ Department of Chemistry, Graduate School of Natural Science and Technology, Okayama University, \\ Okayama 700-8530, Japan
}

\begin{abstract}
Microfluidic paper-based analytical devices ( $\mu$ PADs) were used to detect the iron ion content in the water of a natural hot spring in order to assess the applicability of this process to the environmental analysis of natural water. The $\mu$ PADs were fabricated using a wax printer after the addition of hydroxylamine into the detection reservoirs to reduce $\mathrm{Fe}^{3+}$ to $\mathrm{Fe}^{2+}$, 1,10-phenanthroline for the forming of a complex, and poly(acrylic acid) for ion-pair formation with an acetate buffer ( $\mathrm{pH}$ 4.7). The calibration curve of $\mathrm{Fe}^{3+}$ showed a linearity that ranged from 100 to $1000 \mathrm{ppm}$ in the semi-log plot whereas the color intensity was proportional to the concentration of $\mathrm{Fe}^{3+}$ and ranged from 40 to $350 \mathrm{ppm}$. The calibration curve represented the daily fluctuation in successive experiments during four days, which indicated that a calibration curve must be constructed for each day. When freshly prepared $\mu$ PADs were compared with stored ones, no significant difference was found. The $\mu$ PADs were applied to the determination of $\mathrm{Fe}^{3+}$ in a sample of water from a natural hot spring. Both the accuracy and the precision of the $\mu \mathrm{PAD}$ method were evaluated by comparisons with the results obtained via conventional spectrophotometry. The results of the $\mu$ PADs were in good agreement with, but less precise than, those obtained via conventional spectrophotometry. Consequently, the $\mu$ PADs offer advantages that include rapid and miniaturized operation, although the precision was poorer than that of conventional spectrophotometry.
\end{abstract}

Keywords Microfluidic paper-based analytical device, environmental analysis, iron ion, hot spring

(Received July 6, 2015; Accepted September 1, 2015; Published January 10, 2016)

\section{Introduction}

Metal ions are a major pollutant of the global environment since they frequently accumulate in plants ${ }^{1}$ and fish, ${ }^{2}$ which results in overconsumption by the animals that feed on them. Metal ions also exist in particulate matter in the air, ${ }^{3}$ and are produced by industrial and life activity. Therefore, the monitoring of metal ions is an important task for protecting and improving the global environment.

In the analysis of metal ions, atomic absorption spectrometry, inductively coupled plasma optical emission spectrometry, and inductively coupled plasma mass-spectrometry are employed conventionally for routine analysis since they are highly selective and sensitive. ${ }^{3}$ However, operations that use these instruments are, in general, limited to the laboratory so that samples must be carefully taken and stored in the field with appropriate pretreatment, such as the addition of acid, the use of clean bottles, and cooling. Thus, proper on-site measurement simplifies the sampling process and prevents contamination of the samples.

Recently, microfluidic paper-based analytical devices ( $\mu$ PADs) have attracted a great deal of interest in several fields including bioanalysis and environmental analysis due to their simple structure, easy fabrication, weight reduction, inexpensive materials, and rapid analysis. ${ }^{4,5} \mu$ PADs have shown promise for

$\dagger$ To whom correspondence should be addressed.

E-mail: kaneta@okayama-u.ac.jp their use in point-of-care testing during bioanalysis, as described in many publications. ${ }^{6-16}$ When used in environmental analysis, $\mu$ PADs have been successfully applied to the measurement of metal ions in particulate matters (PMs), ${ }^{17-19}$ as well as being useful for measuring the oxidative activity of PMs. ${ }^{20}$ We also reported the rapid use of $\mu$ PADs in acid-base titrations during the on-site analysis of acidic water in a natural hot spring. ${ }^{21}$

During the environmental analysis of PMs, Henry's group used the high sensitivity of $\mu$ PADs to determine that metal ions are major components. ${ }^{17-19}$ The degree of precision in that research was relatively poor, however, with relative standard deviations in the determination of iron ion $\left(\mathrm{Fe}^{3+}\right)$ that were 6 to $12 \%$ for standard solutions and $26 \%$ for a practical sample. ${ }^{17}$

In the present study, we evaluated the precision and accuracy of $\mu$ PADs for the determination of $\mathrm{Fe}^{3+}$ in order to apply them to the analysis of the water in a natural hot spring. We determined the concentration of $\mathrm{Fe}^{3+}$ in the hot spring water using the $\mu$ PADs, and compared the results with those obtained by conventional spectrophotometry.

\section{Experimental}

\section{Materials}

All reagents were of analytical grade and were used without further purification. All solutions were prepared with deionized water purified by means of an Elix water purification system (Millipore Co., Ltd., Molsheim, France). Sodium acetate, 1,10-phenanthroline (phen) monohydrate, hydroxylamine, and 
an iron standard solution (1000 ppm) were purchased from Wako Pure Chemical Industries (Osaka, Japan). Acetic acid was obtained from Kanto Chemical (Tokyo, Japan). Nitric acid was purchased from Mitsubishi Chemical (Tokyo, Japan). A poly(acrylic acid) solution (average $M_{\mathrm{w}} \sim 250000,35 \mathrm{wt} \%$ in water) was obtained from Sigma-Aldrich (St. Louis, MO). A stock solution of $6.3 \mathrm{M}$ acetate buffer ( $\mathrm{pH} 4.7$ ) was prepared by dissolving appropriate amounts of acetic acid and sodium acetate in water. Solutions of hydroxylamine and phen were prepared by dissolving appropriate amounts in the acetate buffer to concentrations of $0.1 \mathrm{~g} \mathrm{~mL}^{-1}$ and $16 \mathrm{mg} \mathrm{mL}^{-1}$, respectively. A $5.6 \mathrm{mg} \mathrm{mL}^{-1}$ poly(acrylic acid) solution was prepared by diluting the $35 \%$ solution with water. For conventional spectrophotometry, $5 \%$ hydroxylamine, $5.4 \mathrm{mM}$ phen, and $1 \mathrm{M}$ acetate buffer were prepared with deionized water.

\section{$\mu P A D$ fabrication}

The $\mu$ PADs used in the present study were fabricated according to a procedure reported by Henry's group. ${ }^{17}$ The pattern of the $\mu$ PAD was drawn using Microsoft Office Power Point 2013 so as to locate a sample reservoir at the center with four detection reservoirs arranged radially in a $30 \times 30 \mathrm{~mm}$ square. The $\mu$ PADs were printed on a sheet of filter paper $\left(200 \times 200 \mathrm{~mm}\right.$, Chromatography Paper 1CHR, Whatman ${ }^{\mathrm{TM}}$, GE Healthcare Lifesciences, UK) using a wax printer ${ }^{22}$ (ColorQube $8570 \mathrm{DN}$, Xerox, Norwalk, CT), followed by heating at $150^{\circ} \mathrm{C}$ for $2 \mathrm{~min}$ in a drying machine (ONW-300S, AS ONE Corp.). The backside of the printing surface was covered with clear packing tape to prevent the solution from leaking out underneath the $\mu \mathrm{PAD}$. The $\mu \mathrm{PADs}$ were prepared by applying appropriate volumes of reagent solutions to the detection reservoirs via a microsyringe or a micropipette; $1 \mu \mathrm{L}$ of $0.1 \mathrm{~g} \mathrm{~mL}^{-1}$ hydroxylamine and $0.3 \mu \mathrm{L}$ of $5.6 \mathrm{mg} \mathrm{mL}^{-1}$ poly(acrylic acid) were added to the four detection reservoirs, followed by two $0.2-\mu \mathrm{L}$ aliquots of $16 \mathrm{mg} \mathrm{mL}^{-1}$ phen in $6.3 \mathrm{M}$ acetate buffer ( $\mathrm{pH} 4.7$ ). The $\mu$ PAD was dried completely between each addition of reagent solution.

\section{Analytical procedure}

In the analysis, $25 \mu \mathrm{L}$ of a sample solution was introduced into the center of the $\mu \mathrm{PAD}$ using a micropipette. After all the channels and reservoirs were filled with the sample solution, the $\mu \mathrm{PAD}$ was dried, and then scanned (CanoScan LiDE 500F, Canon, Tokyo, Japan) to obtain electronic images. The color intensity of each detection reservoir in the scanned images was measured using the public domain software ImageJ (National Institutes of Health). ${ }^{17}$ In general, each sample was introduced into $5 \mu$ PADs printed on a piece of paper so that the color intensities of the 20 reservoirs could be averaged for the sample. The average intensity was plotted against the concentrations of $\mathrm{Fe}^{3+}$ and their logarithms in order to construct the calibration curve. A schematic illustration of the experimental procedure including fabrication of the $\mu$ PADs and operations is shown in Fig. 1(A).

\section{Analysis of the water from a natural hot spring}

An acidic water sample from a natural hot spring was collected at the source of the Tsukahara Onsen hot spring, Yufu, Oita, Japan. Water was taken from a pool near a spa $\left(40^{\circ} \mathrm{C}\right)$ and was mixed with $2 \mathrm{M} \mathrm{HNO}_{3}$ at a volume ratio of $1: 1$ to avoid the precipitation of $\mathrm{Fe}^{3+}$.

In the spectrophotometric measurements, the hot spring water sample was diluted 10 -fold with water. The diluted sample and the standard solutions containing 1, 3, 5, 7, and $10 \mathrm{ppm}$ of $\mathrm{Fe}^{3+}$ were reacted with phen as follows: $10-\mathrm{mL}$ aliquots of the sample

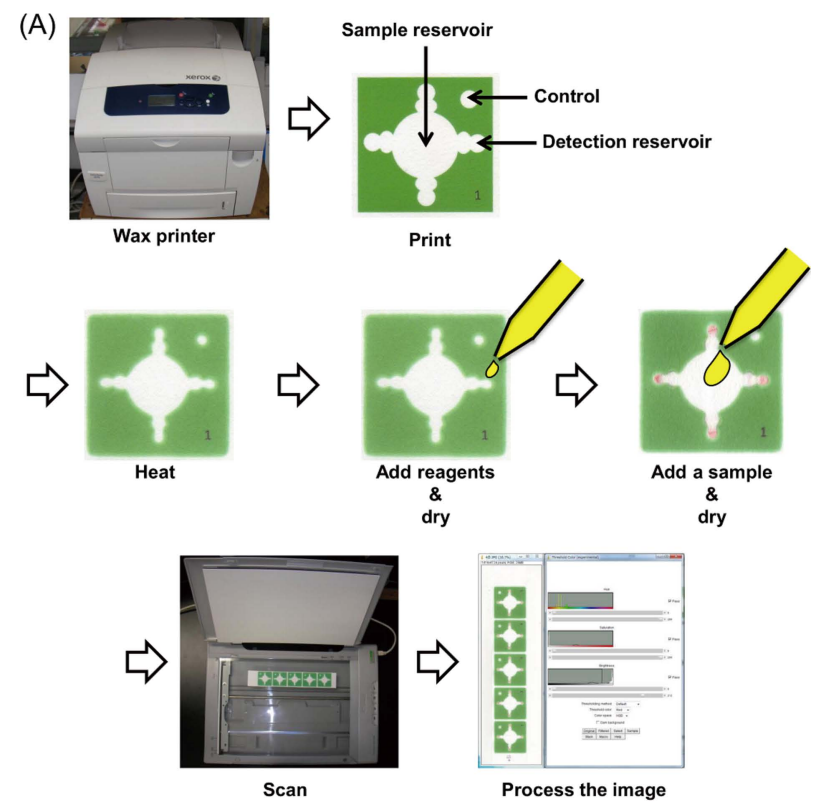

(B)

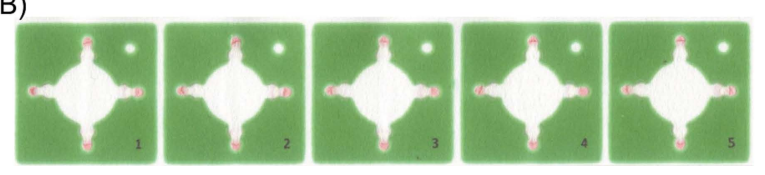

Fig. 1 Schematic illustration of the experiments. (A) Fabrication and operation of the $\mu$ PADs. (B) Measurements of a standard solution by the $\mu$ PADs. Sample concentrations: $100 \mathrm{ppm} \mathrm{Fe}^{3+}$, sample volume; $25 \mu \mathrm{L}$ for each device. The experimental conditions are given in the text.

solution and the standard solutions were taken into $25 \mathrm{~mL}$ volumetric flasks, and then $5 \mathrm{~mL}$ of $5 \%$ hydroxylamine and $5 \mathrm{~mL}$ of $5.4 \mathrm{mM}$ phen were added to each volumetric flask. Finally, the volume was adjusted to $25 \mathrm{~mL}$ with $1 \mathrm{M}$ of acetate buffer ( $\mathrm{pH}$ 4.7). Absorbance at $510 \mathrm{~nm}$ was measured by the spectrophotometer using a $1-\mathrm{cm}$ cuvette.

\section{Results and Discussion}

\section{Calibration curve}

Initially, we constructed calibration curves of $\mathrm{Fe}^{3+}$ to assess the sensitivity and precision in the determination of $\mathrm{Fe}^{3+}$ using the $\mu$ PADs. The results for a standard solution of $100 \mathrm{ppm} \mathrm{Fe}^{3+}$ are shown in Fig. 1(B). The average color intensity for the 20 detection reservoirs in Fig. 1(B) was measured at $(16.17 \pm 0.73) \times 10^{4}$, which would be acceptable for practical analysis since the relative standard deviation was less than $5 \%$.

The relationship between the concentration of $\mathrm{Fe}^{3+}$ and the color intensities ranging from 20 to $1000 \mathrm{ppm}$ is also shown in Figs. 2(A) and 2(B). The relationship between the logarithm of the concentration and the color intensity was linear and ranged from 100 to $1000 \mathrm{ppm}$ (Fig. 2(A)). The dependence of the color intensity on the concentration also was linear and ranged from 40 to $350 \mathrm{ppm}$ with a correlation coefficient $\left(R^{2}\right)$ of 0.9945 , while the saturation of the color intensity was above $350 \mathrm{ppm}$ (Fig. 2(B)). The limit of quantification (LOQ) was estimated at $40 \mathrm{ppm}$, which was the minimum concentration that could be distinguished by the image processing software when the threshold of the color intensity was adjusted to the minimum 

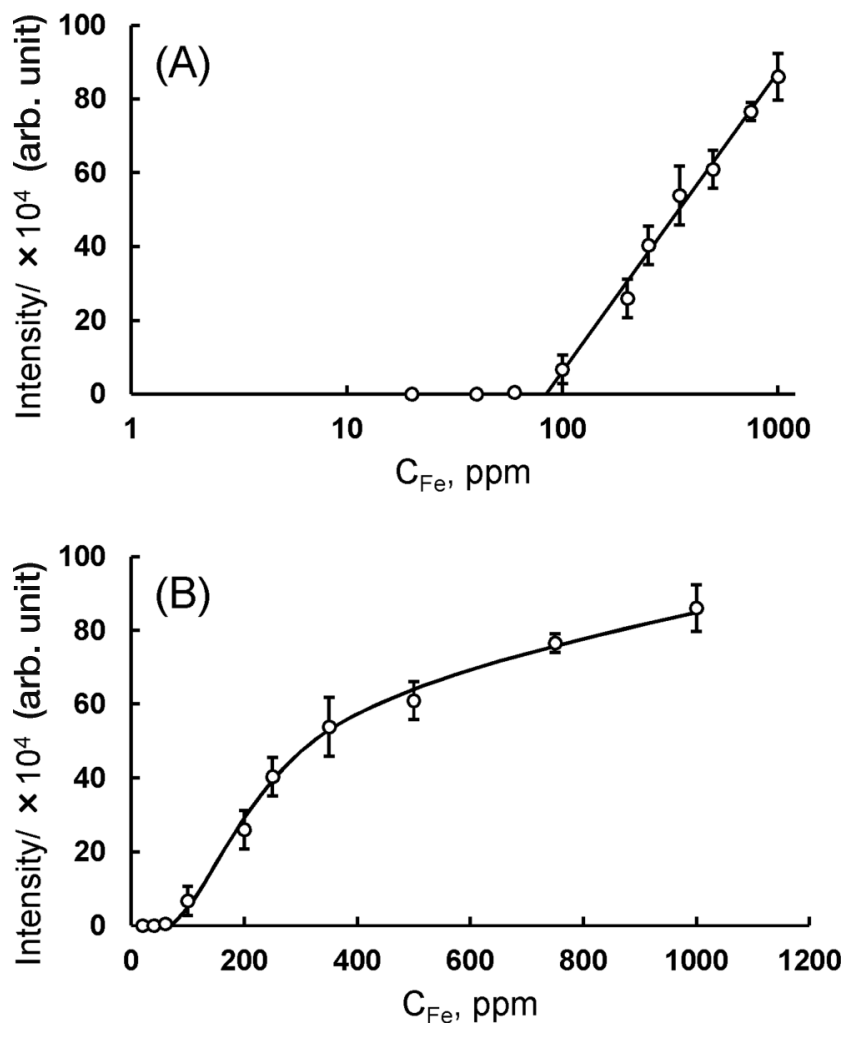

Fig. 2 Calibration curves of $\mathrm{Fe}^{3+}$. (A) Semi-log plot, (B) linear plot. The experimental conditions are given in the text. Error bars show the standard deviations.

value of zero, which was the intensity of the blank. The LOQ was comparable to that reported by Mentele et al. ${ }^{16}(1.5 \mu \mathrm{g}$ in $30 \mu \mathrm{L}, 50 \mathrm{mg} \mathrm{L}^{-1}$ ) while Asano et al. found a lower LOQ $\left(13.8 \mu \mathrm{M}, 0.771 \mathrm{mg} \mathrm{L}^{-1}\right)$ using a paper device with test spots where no diffusion happened since a single spot was used as a reservoir. ${ }^{23}$ Thus, the spot-type paper device was preferable for enhancing the sensitivity, although the throughput was lowered since a sample had to be added to several spots for multiple measurements, which meant that Asano's device took four-times longer than either Mentele's or ours during the respective sample introductions. In terms of the sample volume, Asano et al. needed $20 \mu \mathrm{L}$ for a single measurement, whereas we used $25 \mu \mathrm{L}$ of a sample to acquire four types of data $(6.25 \mu \mathrm{L}$ for a single measurement), which was similar to Mentele's device that required $30 \mu \mathrm{L}$ for a device with four detection reservoirs. Therefore, the sample consumption of our device was comparable to Mentele's device and was much lower than Asano's device.

To evaluate the stability of the $\mu$ PADs, intraday and day-byday precisions were assessed by successive measurements during four days. In the measurements, we employed two types of $\mu$ PADs each day; one type was freshly prepared and the other was prepared on the first day then stored in the dark. The calibration curves obtained by the freshly prepared $\mu$ PADs and the stored $\mu$ PADs are shown in Table 1 (the standard solutions contained 40, 100, 200, and $350 \mathrm{ppm} \mathrm{Fe}^{3+}$ ). The calibration curves varied considerably from day to day whereas the slopes between the freshly prepared $\mu$ PADs and the stored $\mu$ PADs showed fewer significant differences during the day. For example, the relative difference in the slopes was $-0.4 \%$ for the third day and $0.8 \%$ for the fourth day, although it was slightly
Table 1 Reproducibility of calibration curves for $\mathrm{Fe}^{3+}$

\begin{tabular}{ccc}
\hline & Freshly-prepared & Stored \\
\hline \multirow{2}{*}{ 1st day } & $y=0.142 x-6.238$ & - \\
& $\left(R^{2}=0.987\right)$ & \\
2nd day & $y=0.194 x-1.587$ & $y=0.175 x-6.96$ \\
& $\left(R^{2}=0.999\right)$ & $\left(R^{2}=0.997\right)$ \\
3rd day & $y=0.269 x+1.474$ & $y=0.270 x-11.891$ \\
& $\left(R^{2}=0.997\right)$ & $\left(R^{2}=0.994\right)$ \\
4th day & $y=0.247 x-1.6245$ & $y=0.245 x-10.710$ \\
& $\left(R^{2}=0.974\right)$ & $\left(R^{2}=0.980\right)$ \\
\hline
\end{tabular}

$R$ is the correlation coefficient.

Table 2 The concentration of $\mathrm{Fe}^{3+}$ in the hot spring water sample

\begin{tabular}{lcc}
\hline & $\begin{array}{c}\text { Spectrophotometry } \\
(n=3), \mathrm{ppm}\end{array}$ & $\begin{array}{c}\mu \mathrm{PAD} \\
(n=4)^{\mathrm{a}}, \mathrm{ppm}\end{array}$ \\
\hline Mean & 107.8 & 112.1 \\
Standard deviation & 2.3 & 11.3 \\
Confidence interval (95\%) & \pm 2.6 & \pm 11.1 \\
\hline
\end{tabular}

a. The sample was determined in four successive days in which the calibration curve was constructed each day. Five $\mu$ PADs consisting of four detection reservoirs were employed for the measurement of the sample and the mean value was obtained using the results of 20 detection reservoirs. Thus, the number of measurements represents the number of days to measure the sample.

larger for the second day $(9.8 \%)$. Conversely, the slopes for different days varied from 0.142 to $0.269(89 \%)$ in the freshly prepared $\mu$ PADs and from 0.175 to $0.270(54 \%)$ in the stored $\mu$ PADs. It should be noted that the color intensities of the freshly prepared $\mu$ PADs were always greater than those of the stored $\mu$ PADs, which may imply that the $\mu$ PADs were degraded slightly, even when stored in the dark. These results suggest that the calibration curve must have been constructed on the day the samples were determined.

To optimize the experimental conditions, we measured 60 , 200, and $500 \mathrm{ppm} \mathrm{Fe}^{3+}$ solutions at temperatures of 30, 40, 50, 60,70 , and $80^{\circ} \mathrm{C}$. We also measured the absorbance of a $\mathrm{Fe}$ (phen) $)^{2+}$ complex at 0,20 , and $80^{\circ} \mathrm{C}$ using absorption spectrometry. In both methods, the differences in the absorbance, or the color intensity, of the $\mathrm{Fe}(\mathrm{phen})_{3}{ }^{2+}$ complex was almost independent of temperature change. These results are quite reasonable in terms of the thermodynamic parameters of the complex formation between $\mathrm{Fe}^{2+}$ and phen. Calorimetry ${ }^{24}$ showed the enthalpy and entropy of the complex formation to be $-28.5 \mathrm{kcal} \mathrm{mol}^{-1}$ and $-15.4 \mathrm{cal} \mathrm{mol}^{-1} \mathrm{~K}^{-1}$, and the stability constants of the complex $\left(\log \beta_{3}\right)$ were 22.96 at $1{ }^{\circ} \mathrm{C}$ and 17.07 at $80^{\circ} \mathrm{C}$, respectively. These constants were so large that the complex formation took place quantitatively even at a high temperature. Therefore, there was no need to control the temperature in the measurement of $\mathrm{Fe}^{3+}$, and the measurements could be carried out at room temperature.

\section{Analysis of the water from a natural hot spring}

To demonstrate the applicability of $\mu$ PADs to the analysis of natural water, the $\mathrm{Fe}^{3+}$ in a sample of water from a natural hot spring was determined at room temperature and the results were compared with those from conventional spectrophotometry, as shown in Table 2. Assuming a 95\% confidence interval, the concentration was determined to be $107.8 \pm 2.6 \mathrm{ppm}$ by 
conventional spectrophotometry and $112.1 \pm 11.1 \mathrm{ppm}$ by the $\mu$ PADs. Therefore, the results of the $\mu$ PADs were comparable to those from conventional spectrophotometry, although the precision of the $\mu$ PADs was slightly poorer. These results indicate that the $\mu$ PADs would be advantageous based on facile and rapid operation, which makes them suitable for rough estimations of concentration.

\section{Conclusions}

We assessed the precision and accuracy of $\mu$ PADs when used in the determination of $\mathrm{Fe}^{3+}$. It was clear that calibration curves must be constructed for each measurement since the slope showed day-by-day fluctuations. We also demonstrated that the $\mu$ PADs were applicable to the determination of $\mathrm{Fe}^{3+}$ in the water of a natural hot spring. The $\mu$ PADs were useful for a simple assay of the $\mathrm{Fe}^{3+}$ in natural water samples because of easy operation, lightness and affordability, although conventional spectrophotometry provides a more precise and sensitive determination.

\section{Acknowledgements}

This research was supported by The Yakumo Foundation for Environmental Science and Grants-in-Aid for Scientific Research, Scientific Research (B) (No. 26288067) from the Japan Society for the Promotion of Science.

\section{References}

1. P. C. Nagajyoti, K. D. Lee, and T. V. M. Sreekanth, Environ. Chem. Lett., 2010, 8, 199.

2. M. I. Castro-Gonzalez and M. Mendez-Armenta, Environ. Toxicol. Pharmacol., 2008, 26, 263.

3. G.-C. Fang, Y.-S. Wu, S.-H. Huang, and J.-Y. Rau, Atmos. Environ., 2005, 39, 3003.

4. A. W. Martinez, S. T. Phillips, M. J. Butte, and G. M
Whitesides, Angew. Chem., Int. Ed., 2007, 46, 1318.

5. D. D. Liana, B. Raguse, J. J. Gooding, and E. Chow, Sensors, 2012, 12, 11505

6. A. K. Yetisen, M. S. Akram, and C. R. Lowe, Lab Chip, 2013, 13, 2210.

7. D. M. Cate, J. A. Adkins, J. Mettakoonpitak, and C. S. Henry, Anal. Chem., 2015, 87, 19.

8. A. W. Martinez, S. T. Phillips, G. M. Whitesides, and E. Carrilho, Anal. Chem., 2010, 82, 3.

9. H. Noh and S. T. Phillips, Anal. Chem., 2010, 82, 8071.

10. S. Li, J. A. Hagen, and I. Papautsky, Lab Chip, 2012, 12, 4240.

11. K. M. Schilling, D. Jauregui, and A. W. Martinez, Lab Chip, 2013, 13, 628.

12. G. G. Lewis, J. S. Robbins, and S. T. Phillips, Anal. Chem., 2013, 85, 10432.

13. J. I. Hong and B.-Y. Chang, Lab Chip, 2014, 14, 1725.

14. R. Gerbers, W. Foellscher, H. Chen, C. Anagnostopoulos, and M. Faghri, Lab Chip, 2014, 14, 4042.

15. K. Yamada, S. Takaki, N. Komuro, K. Suzuki, and D. Citterio, Analyst, 2014, 139, 1637.

16. M. M. Mentele, J. Cunningham, K. Koehler, J. Volckens, and C. S. Henry, Anal. Chem., 2012, 84, 4474.

17. P. Rattanarat, W. Dungchai, D. M. Cate, W. Siangproh, J. Volckense, O. Chailapakul, and C. S. Henry, Anal. Chim. Acta, 2013, 800, 50.

18. J.-Y. Sun, C.-M. Cheng, and Y.-C. Liao, Anal. Sci., 2015, $31,145$.

19. D. M. Cate, P. Nanthasurasak, P. Riwkulkajorn, C. L'Orange, C. S. Henry, and J. Volckens, Ann. Occup. Hyg., 2014, 58, 413.

20. Y. Sameenoi, P. Panymeesamer, N. Supalakorn, K. Koehler, O. Chailapakul, C. S. Henry, and J. Volckens, Environ. Sci. Technol., 2013, 47, 932.

21. S. Karita and T. Kaneta, Anal. Chem., 2014, 86, 12108.

22. E. Carrilho, A. W. Martinez, and G. M. Whitesides, Anal. Chem., 2009, 81, 7091.

23. H. Asano and Y. Shiraishi, Anal. Chim. Acta, 2015, 883, 55.

24. G. Andregg, Helv. Chim. Acta, 1963, 46, 2813. 